\title{
Secondary Structure-Dependent Physicochemical Interaction of Oligonucleotides with Gold Nanorod and Photothermal Effect for Future Applications: A New Insight
}

\author{
Upasana Das, ${ }^{\dagger}$ Aditi Sahoo, ${ }^{\ddagger}$ Subhash Haldar, ${ }^{\S}$ Sudin Bhattacharya, ${ }^{\dagger}$ Syam Sundar Mandal, ${ }^{\dagger}$
} William H. Gmeiner," and Supratim Ghosh*,†

${ }^{\dagger}$ Department of Anti-Cancer Drug Development and Chemotherapy, Chittaranjan National Cancer Institute, 37, S.P. Mukherjee
Road, Kolkata 700026, India
${ }^{\ddagger}$ Advanced Mechanical and Materials Characterization Division, CSIR-Central Glass and Ceramic Research Institute, 196, Raja S. C.
Mullick Road, Jadavpur, Kolkata 700032, India
${ }^{\S}$ Department of Medicine, Samuel Oschin Comprehensive Cancer Institute, Cedars-Sinai Medical Center, Los Angeles, California
90048, United States
${ }^{\|}$Department of Cancer Biology, Wake Forest University School of Medicine, Winston-Salem, North Carolina 27157, United States

Supporting Information

\begin{abstract}
We investigate the physicochemical interactions of gold nanorod (GNR) with single-stranded, doublestranded, and hairpin DNA structures to improve the biological compatibility as well as the therapeutic potential, including the photothermal effect of the conjugates. Studies have demonstrated that different DNA secondary structures, containing thiol group, have different patterns of physicochemical interaction. Conjugation efficiency of paired oligonucleotides are significantly higher than that of oligonucleotides with naked bases. Furthermore, hairpinshaped DNA structures are most efficient in terms of

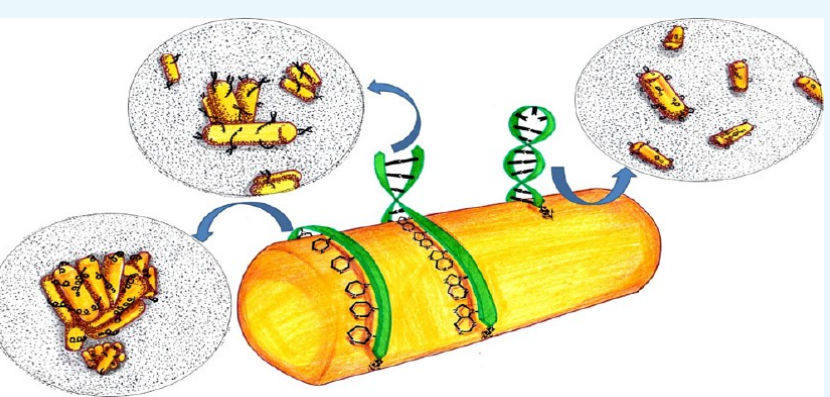
conjugation and increased dispersion, with least interference on GNR near-infrared absorbance and photothermal effect. Our conjugation method can successfully exchange the overall coating of the GNR, attaching the maximum number of DNA molecules, thus far reported. Chemical mapping depicted uniform attachment of thiolated DNA molecules without any topological preference on the GNR surface. Hairpin DNA-coated GNR are suitable for intracellular uptake and remain dispersed in the cellular environment. Finally, we conjugated GNR with 5-fluoro-2'-deoxyuridine-containing DNA hairpin and the conjugate demonstrated significant cytotoxic activity against human cervical cancer cell line (KB). Thus, hairpin DNA structures could be utilized for optimal dispersion and photothermal effect of GNR, along with the delivery of cytotoxic nucleotides, developing the concept of multimodality approach.
\end{abstract}

\section{INTRODUCTION}

Gold nanostructures are versatile and programmable nanomaterials that may be combined with diverse DNA structures for various applications. ${ }^{1-4}$ Gold nanorods (GNRs) have received notable attention due to their unique optical and electronic properties that could be utilized for biomolecule sensing as well as hyperthermia-based therapy. ${ }^{5-7}$ Cell death can be induced above $45{ }^{\circ} \mathrm{C} ;{ }^{8,9}$ thus, photothermal approaches in combination with chemotherapeutic molecules may be useful for cancer treatment. Moreover, these nanoparticles have the potential for molecular targeting in addition to their natural targeting property via enhanced permeability and retention effect. ${ }^{10,11}$ Nanoparticles, such as carbon nanotubes and gold nanorods, are being investigated for hyperthermia-based therapies, utilizing near-infrared (NIR) radiation that can pass through tissues to the deeply located tumors. ${ }^{12,13}$
While carbon nanotubes demonstrate significant toxicity that limits biological applications, ${ }^{14,15}$ surface-modified GNR showed its biocompatibility in vivo. ${ }^{16-18}$ GNRs are nearly always synthesized with cetyltrimethylammonium bromide (CTAB) coating. ${ }^{16} \mathrm{CTAB}$ is a positively charged surfactant that is cytotoxic to normal human tissue. ${ }^{19}$ Furthermore, lowenergy interaction of $\mathrm{CTAB}$ with GNR surface is likely to cause aggregation in vivo, due to dilution in combination with high salt concentration and temperature. ${ }^{16}$ Thus, it is desirable to exchange the overall coating of GNRs with biocompatible molecules, such as oligonucleotides, which have been systematically studied by several research groups. Previously reported

Received: May 11, 2018

Accepted: August 15, 2018

Published: October 30, 2018 
methods performed conjugation of thiolated DNA via roundtrip phase transfer, ${ }^{20}$ vinyl carboxylate-modified cationic surfactant in combination with $\mathrm{NH}_{2}$-modified DNA molecules, ${ }^{21,22}$ direct DNA functionalizing via salt aging ${ }^{23}$ or low $\mathrm{pH}^{24}$ and ligand-exchange approach using poly(vinylpyrrolidone) as intermediate. ${ }^{25}$ The physicochemical interactions of oligonucleotides with GNR have neither been previously studied systematically nor have previous studies reported the efficiency of different DNA structures for conjugation, including their effect on the photothermal potential of GNR and dispersion of the conjugates in biological environment.

For the first time, we have systematically investigated physicochemical interactions of different DNA secondary structures with GNR using analytical spectroscopy and highresolution microscopy, including chemical mapping, to determine their pattern of conjugation and their photothermal effect. The relative efficiencies of conjugation of different DNA structures, single-stranded (ss), double-stranded (ds), and hairpin (hp), are also investigated. Greater loading and efficient conversion of NIR radiation into heat are important considerations to identify the best-suited DNA structure for photothermal as well as multimodality applications. Experimental reports demonstrated that hp-DNA has significantly greater efficiency to be loaded on the GNR with maximum potential for the photothermal effect. High-resolution microscopy depicted that the hp-DNA-GNR conjugate remains monodispersed in the cellular environment without any indication of aggregation and the conjugate is suitable for intracellular uptake. Further, the laser-induced selective delivery of oligonucleotides in cellular environment could be optimized in light of the present study. GNR has been used for selective DNA/RNA delivery without in-depth investigation of the physicochemical properties of the conjugates. ${ }^{22,26}$ Knowledge of the present work should significantly enhance the strategies of future studies in the field. Utilizing our findings, we have successfully conjugated a DNA hairpin containing cytotoxic nucleotide, 5-fluoro-2'-deoxyuridine (FdU), with GNR. The FdU-substituted hairpin was used to estimate the potential anticancer activity, which could be achieved with simultaneous application of GNR-mediated photothermal effect in the presence of FdU-induced cytotoxicity. The conjugate exhibited significant cytotoxicity against $\mathrm{KB}$ cells with and without $808 \mathrm{~nm}$ laser irradiation. These findings demonstrated that the hairpin structure is optimally fitted for coating GNR with maximum amount of cytotoxic oligonucleotide and the resultant conjugate is promising for multimodality treatment.

\section{RESULTS AND DISCUSSION}

Spectroscopic Characterization of GNR Conjugates. UV-vis spectra of the conjugates (Figure 1a) showed that the NIR absorbance band of CTAB-capped GNR is red-shifted from 807 to $826 \mathrm{~nm}$ with a small reduction $(\sim 7 \%)$ in intensity for hp-DNA coating, while ss- and ds-DNA coating caused significant quenching ( 82 and $28 \%$, respectively). ds-DNA conjugation caused a peak broadening effect with a red shift to $853 \mathrm{~nm}$, while ss-DNA binding caused a large blue shift to 751 $\mathrm{nm}$. A significant reduction in the NIR band intensity might have resulted from aggregation and surface plasmon dumping, in the case of ss- as well as ds-DNA conjugation, while change in band wavelength indicates distinctive interaction of different DNA structures with the GNR surface electrons. A character-
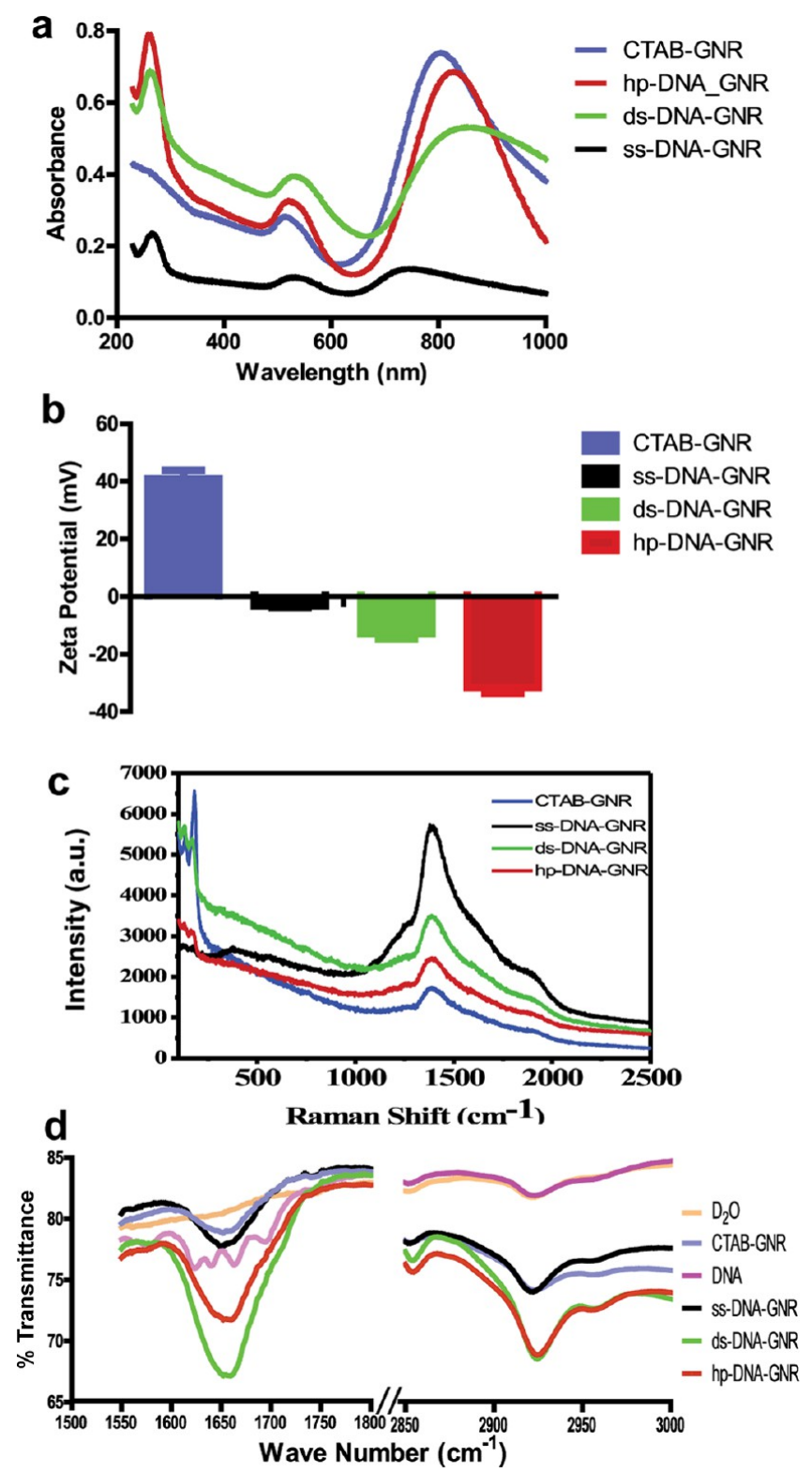

Figure 1. Biophysical characterization of GNR conjugates. (a) UVvis spectra of the GNR conjugates, showing longitudinal SPR band of GNR at $807 \mathrm{~nm}$ for the CTAB-capped GNR, which has been shifted differently with varying intensities for ss-, ds-, and hp-DNA conjugation. The band at $260 \mathrm{~nm}$ suggested DNA conjugation, which is maximum for hp-DNA-GNR and progressively reduced for ds-DNA-GNR as well as ss-DNA-GNR. In the case of CTAB-GNR, there is no band at $260 \mathrm{~nm}$. (b) Graphical representation of $\zeta$ potential of GNR conjugates. Positively charged CTAB-GNR showed a value of $+40.9 \mathrm{mV}$, which has been changed to $-31.6,-12.9$, and $-3.2 \mathrm{mV}$, respectively, for negatively charged hp-, ds-, and ss-DNA conjugation. The error bars represent standard deviation of three independent experimental data sets. (c) Raman spectra of the GNR conjugates, showing a characteristic band at $1390 \mathrm{~cm}^{-1}$. The band has maximum intensity for ss-DNA-GNR and reduces steadily for ds- and hp-coated GNR. (d) Fourier transform infrared (FTIR) spectra of the conjugates, showing characteristic $\mathrm{C}=\mathrm{O}$ band for DNA at $1658 \mathrm{~cm}^{-1}$. Another band at $2925 \mathrm{~cm}^{-1}$ enhanced upon hp- and ds-DNA conjugation region is assigned to $\mathrm{N}-\mathrm{H}$ and $\mathrm{C}-\mathrm{H}$ vibrations.

istic DNA band at $260 \mathrm{~nm}$ was observed in all cases of DNA conjugation that is not present in CTAB-coated GNR. Net absorbance at $260 \mathrm{~nm}$ is maximum for the hp-DNA-GNR 


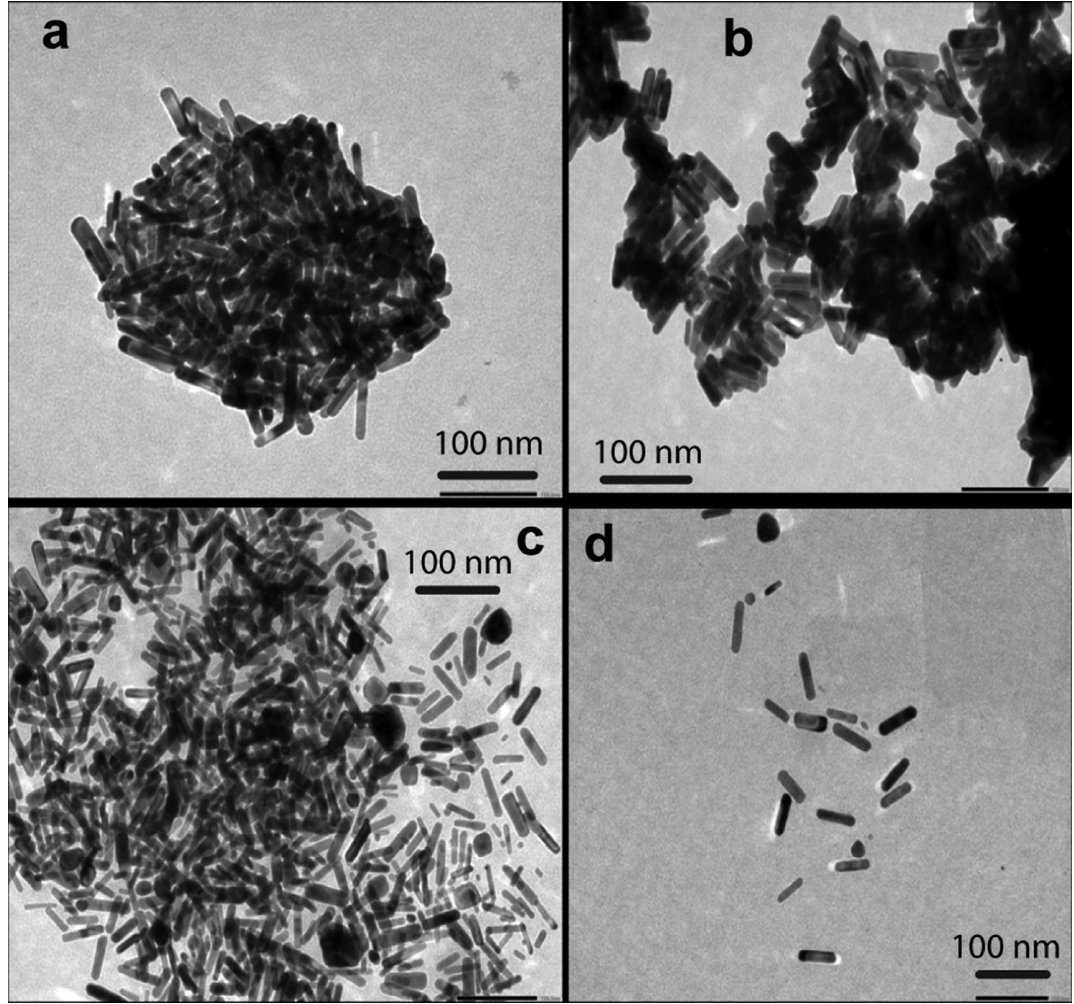

Figure 2. Microscopic characterization of GNR conjugates. Transmission electron microscopy (TEM) images of (a) CTAB-, (b) ss-DNA-, (c) dsDNA-, and (d) hp-DNA-coated GNR with similar magnification (scale bar = $100 \mathrm{~nm}$ ); all samples were washed three times for CTAB removal.

conjugate, indicating the maximum amount of DNA attachment, followed by ds- and ss-DNA-bound GNR.

$\zeta$ potential changed from +40.9 to $-31.6 \mathrm{mV}$ for hp-DNA conjugation (Figure $1 \mathrm{~b}$ ), suggesting the successful exchange of GNR coating and removal of CTAB. In the case of ss- and dsDNA conjugation, the $\zeta$ potential values were -3.2 and -12.9 $\mathrm{mV}$, respectively. Moreover, high-magnitude $\zeta$ potential of the hp-DNA-GNR suggested their stability in suspension (Figure $2)$, while lower $\zeta$ potential values of ss- and ds-DNA-bound GNR indicated aggregation. ${ }^{27,28}$

Figure 1c depicts the characteristic Raman spectra of GNR conjugates. A Soret band at $1390 \mathrm{~cm}^{-1}$ is observed in all DNAconjugated as well as CTAB-capped GNR samples. However, the intensity of the band is maximum in the case of ss-DNAcoated GNR, followed by ds-DNA-bound GNR, and minimum for hp-DNA-GNR. The band is assigned to the $\mathrm{C}=\mathrm{O}$ symmetric stretching. ${ }^{29-31}$ The results indicate that unpaired DNA bases are interacting more closely with GNR surface, increasing symmetric stretching of $\mathrm{C}=\mathrm{O}$.

In all cases of DNA-conjugated GNR, FTIR spectra showed the DNA characteristic band at $1658 \mathrm{~cm}^{-1}$ (Figures $1 \mathrm{~d}$ and S1, Supporting Information), assigned to $\mathrm{C}=\mathrm{O}$ stretching vibration. $^{29-31}$ The band is more pronounced in ds-DNAGNR as well as hp-DNA-GNR and significantly reduced in ssDNA-GNR, while it is split into four smaller peaks for only DNA sample, covering the complete region of 1590-1720 $\mathrm{cm}^{-1}$. The formation of a single broad and enhanced peak upon conjugation of DNA molecules on GNR surface indicated a uniform vibrational mode of all $\mathrm{C}=\mathrm{O}$ groups. Another band at $2925 \mathrm{~cm}^{-1}$ significantly enhanced upon conjugation of DNA molecules with GNR, especially in the cases of ds and hp. The band at $2925 \mathrm{~cm}^{-1}$ is assigned to $\mathrm{N}-\mathrm{H}$ or $\mathrm{C}-\mathrm{H}$ vibrations, ${ }^{29-31}$ which is enhanced most likely due to uniform vibrations of the responsible groups.

Microscopic Characterization of GNR Conjugates. TEM images of GNR conjugates (Figures 2 and S2, Supporting Information) clearly demonstrated that ss-DNA conjugation caused notable aggregation, while ds-DNA reduced aggregation and produced some monodispersed GNR conjugates. hp-DNA conjugation remarkably increased GNR dispersion with no sign of aggregation. The removal of $\mathrm{CTAB}$ in the absence of suitable coating agent also caused aggregation. The agglomeration of ss-DNA-coated GNR leads to change in suspension color from brownish red to blackish violet (Figure S3, Supporting Information) and hp-DNA conjugation never demonstrated significant color change, while ds-DNA-attached GNR suspension showed little change in color to purple red with reduction in intensity.

Chemical Mapping of GNR Conjugates. Figures 3 and S4 (Supporting Information) show the images of scanning transmission electron microscopy-energy-dispersive X-ray (STEM-EDX) chemical mapping, to investigate the elemental content of the GNR coating materials. All GNR conjugates were mapped for bromine (magenta). Results depicted traces of bromine in the case of CTAB-coated GNR (top row in Figure S4, Supporting Information), while ss-, ds- and hpDNA-conjugated GNR samples showed no significant bromine traces, indicating efficient removal of CTAB. GNR samples (CTAB: top; ss: second top; ds: third top; and hp: bottom row in Figure 3) were also mapped for sulfur and phosphorus, to confirm the presence of DNA and thiol group, including the topological pattern of conjugation. All three DNA-conjugated GNR samples showed the presence of sulfur (yellow) and phosphorus (green) all over the nanorod surface, suggesting 

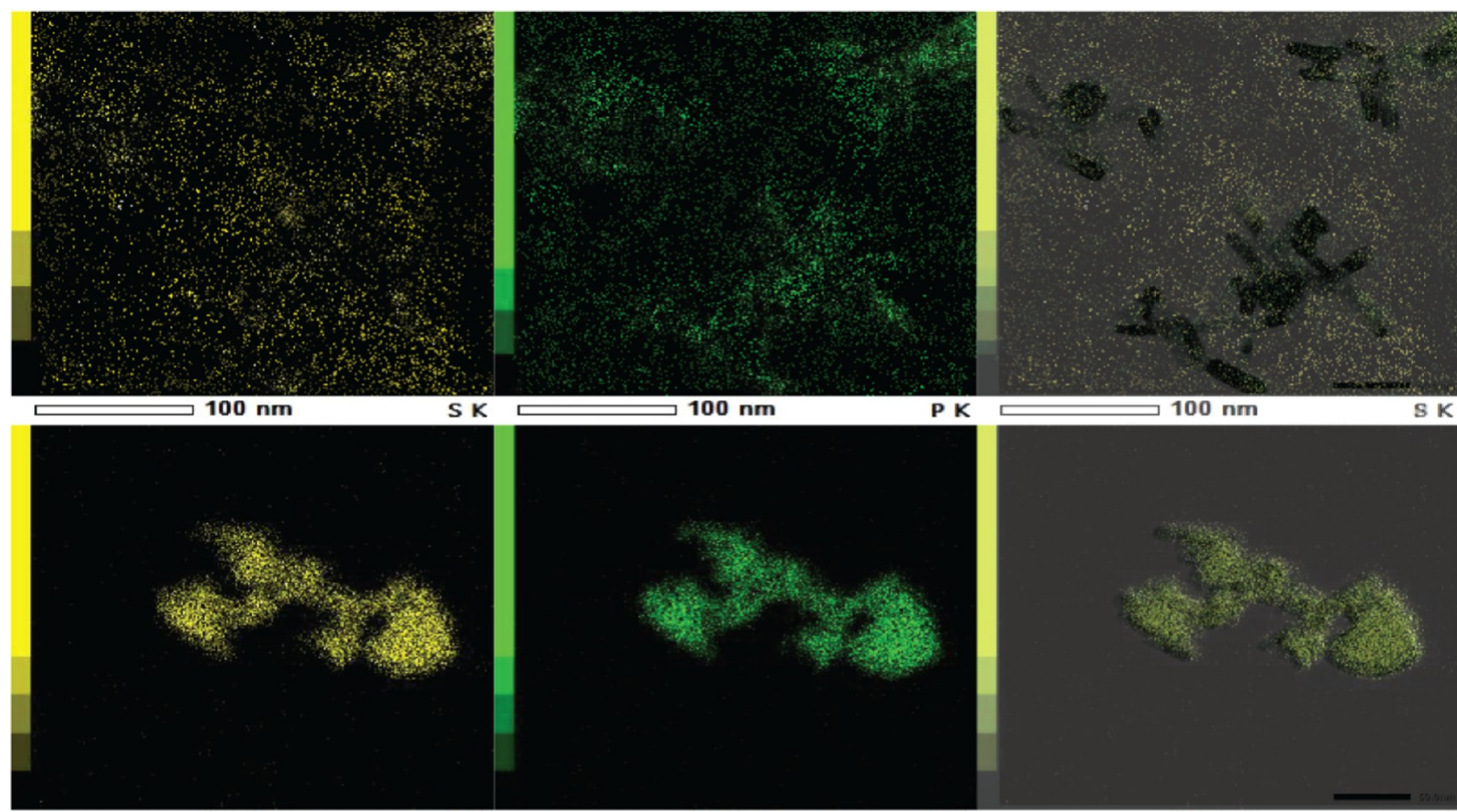

P K

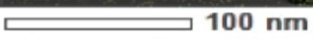

S K

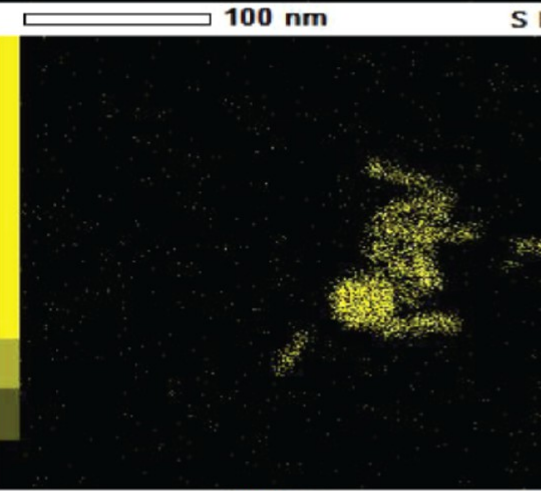

$\mathrm{SK} \longleftarrow 100 \mathrm{~nm}$

P K

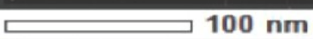

S K
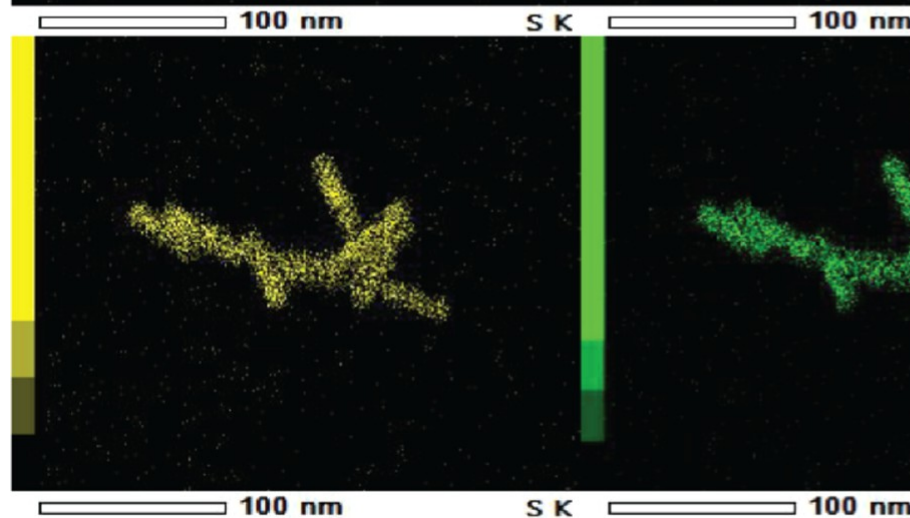

P K

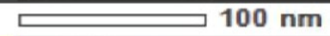

$8 \mathrm{~K}$

$100 \mathrm{~nm}$

S K
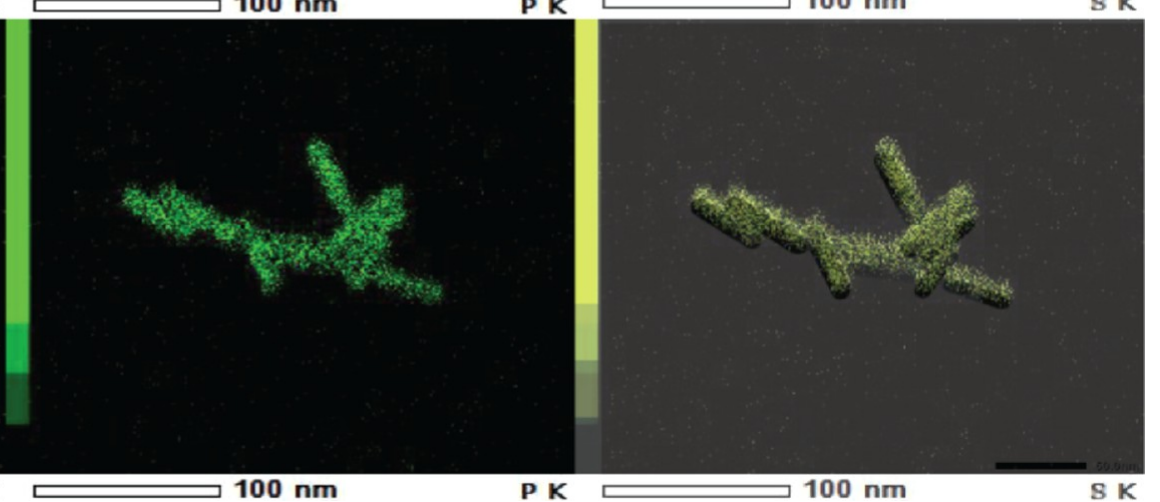

Figure 3. Chemical mapping of GNR conjugates. Images of STEM-EDX chemical mapping. The top row depicts the traces of chemical mapping result of CTAB-GNR sample; from left to right, the images represent the footprints of sulfur (yellow), phosphorus (green), and their overlay with STEM images of GNR. The second row from the top exhibits ss-DNA-GNR chemical mapping traces; from left to right, the images represent sulfur (yellow), phosphorus (green), and overlay of footprints with STEM images of GNR. The third row from the top depicts ds-DNA-GNR and bottom row depicts hp-DNA-GNR chemical mapping traces in a similar order to that mentioned above.

uniform binding pattern of thiolated DNA without any topological preference.

Secondary Structure-Dependent DNA Binding Efficiency. Efficiency of conjugation was calculated to asses to what extent DNA secondary structure contributes to the process of thiolated DNA binding with GNR. Figure 4 shows the UV-vis spectra of total DNA added for conjugation, along with DNA-GNR conjugates and unconjugated DNA left. Figure $4 \mathrm{a}$ and its summary in Figure 4d (top row) demonstrate that ss-DNA has lower efficiency for binding on GNR; only 

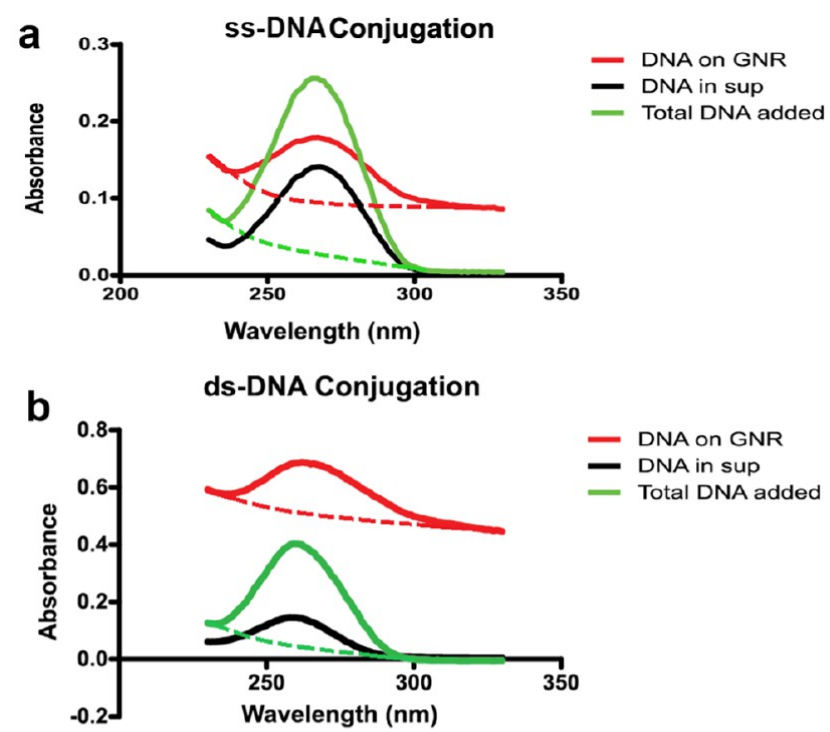

hp-DNA Conjugation
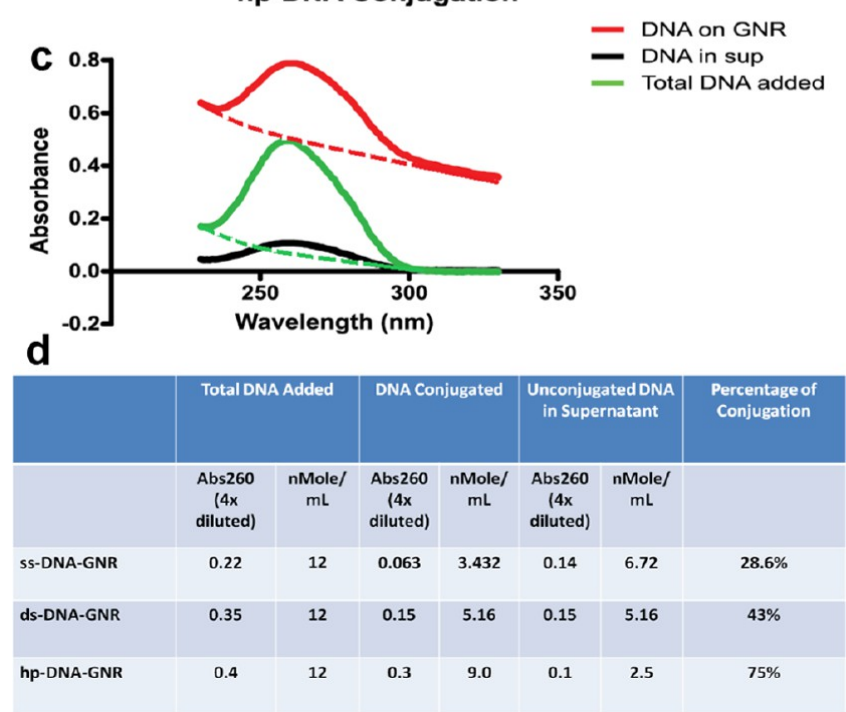

Figure 4. Estimation of conjugation efficiencies of ss-, ds-, and hpDNA structures. (a) UV-vis spectra of the ss-DNA-GNR conjugate along with total DNA added for conjugation and unconjugated DNA left, after four times dilution in all cases. Net absorbance at $260 \mathrm{~nm}$ is calculated after trending base line normalization, as shown by the dotted line, for the estimation of DNA present in each sample. (b) UV-vis spectra of ds-DNA conjugation presented in a similar manner to ss-DNA. (c) UV-vis spectra of hp-DNA conjugation with GNR, presented in a similar manner. (d) Summary of conjugation efficiencies of (a)-(c). All absorbance at $260 \mathrm{~nm}$ was measured with four times dilution, as mentioned; corresponding DNA concentrations calculated with dilution factor multiplication.

$28.6 \%$ of the total DNA added was conjugated. Percentage of binding progressively increased to $43 \%$ for ds-DNA (Figure $4 \mathrm{~b}, \mathrm{~d}$, middle row) and to $75 \%$ for hp-DNA (Figure $4 \mathrm{c}, \mathrm{d}$, bottom row). In terms of number, approximately 957 ss-, 1439 ds-, and 2510 hp-DNA molecules were conjugated on each GNR (Figure S5c, Supporting Information), which are significantly higher than those reported in previous studies. ${ }^{5,22,24}$ The lower amount of DNA attachment in case of ss might have resulted from aggregation during conjugation (Figures 2b and S2d, Supporting Information) and/or more coverage of GNR surface area by each DNA molecule due to horizontal layering. While one ss-DNA molecule covered 1.15 $\mathrm{nm}^{2}$ surface area on the GNR, ds- and hp-DNA molecules covered 0.76 and $0.44 \mathrm{~nm}^{2}$, respectively. A high amount of binding in the case of hp-DNA might have resulted from greater GNR dispersion and vertical orientation of hairpin molecules on the GNR surface. Intermediate binding amount of ds-DNA might have generated from partial horizontal layering as well as vertical orientation on the GNR surface. In the case of ss-DNA, high-resolution TEM images clearly exhibited the presence of a sticky matrix between nanorods, which could have been produced from ss-DNA and CTAB interaction, causing aggregation (Figure S2d, Supporting Information; red square marked region).

Photothermal Effect of the GNR Conjugates. The heating potential of GNR conjugates were evaluated to determine the role of DNA secondary structures on the photothermal effect of GNR. Aqueous suspensions of concentrations 150,300 , and $600 \mu \mathrm{g} / \mathrm{mL}$ of the conjugates were irradiated by $808 \mathrm{~nm}$ continuous wave laser, with powers of $1.0,1.5$, and $2.0 \mathrm{~W}$ for 30,60 , and $120 \mathrm{~s}$. Representative graphs displaying the laser power-, time-, and concentrationdependent heating are exhibited in Figures 5 and S6-S8, Supporting Information. Conjugation of hp-DNA demonstrated the maximum photothermal effect, while ss- and ds-DNA binding reduced the heating efficiency of GNR. The vast majority of comparisons had $p$-values less than 0.05 with many less than 0.01 . For example, while a laser power of $1.1 \mathrm{~W}$ is required to increase the temperature by $3{ }^{\circ} \mathrm{C}$ of a $300 \mu \mathrm{g} / \mathrm{mL}$ hp-DNA-GNR suspension with an irradiation time $60 \mathrm{~s}$, the same extent of temperature increase in similar conditions required $1.71 \mathrm{~W}$ for ds-DNA-GNR and it cannot be achieved for ss-DNA-GNR even with $2.0 \mathrm{~W}$ laser power (Figures 5a and S6, Supporting Information). Thus, hp-DNA-functionalized GNR should be able to achieve biologically relevant heating at lower laser power, which can reduce the surrounding tissue damage in the case of in vivo applications. ${ }^{8,13}$

The linear time-dependent heating of GNR conjugates for a given concentration and laser power is informative to identify conditions suitable for therapeutically relevant hyperthermia. For example, a $5{ }^{\circ} \mathrm{C}$ temperature increase can be obtained by irradiating a $300 \mu \mathrm{g} / \mathrm{mL}$ hp-DNA-GNR conjugate with $1.5 \mathrm{~W}$ laser beam for $33 \mathrm{~s}$, while the same temperature increase requires 56 and $87 \mathrm{~s}$, respectively, in the cases of ds- and ssDNA-conjugated GNR, under identical conditions (Figures $5 \mathrm{~b}$ and S7, Supporting Information)..$^{8,9}$

Requirement of hp-DNA-coated GNR concentration is significantly lower compared to the ss- and ds-DNAconjugated GNR. For example, while an hp-DNA-GNR concentration of $175 \mu \mathrm{g} / \mathrm{mL}$ is required for a $7{ }^{\circ} \mathrm{C}$ temperature increase upon $1.5 \mathrm{~W}$ laser irradiation for $60 \mathrm{~s}$, a similar temperature increase cannot be achieved for ss- as well as dsDNA-coated GNR even with $600 \mu \mathrm{g} / \mathrm{mL}$ concentration under identical conditions (Figures $5 \mathrm{c}$ and S8, Supporting Information). Therefore, hp-DNA-GNR conjugates can achieve biologically relevant heating at lower concentrations, which are more likely to be delivered in vivo. ${ }^{8,9}$

Stability of hp-DNA-GNR Conjugates in Biologically Relevant Conditions in Vitro. The above experimental results demonstrated that hp-DNA has maximum uploading efficiency and produce dispersed nanoconjugates, including greater photothermal effect, and therefore suitable for future biomedical applications. The stability of the hp-DNA-GNR conjugate was evaluated in biologically relevant conditions. hp- 
a $\Delta \mathrm{T}_{\max }$ vs Laser Power $(60 \mathrm{~s}, 300 \mu \mathrm{g} / \mathrm{ml})$

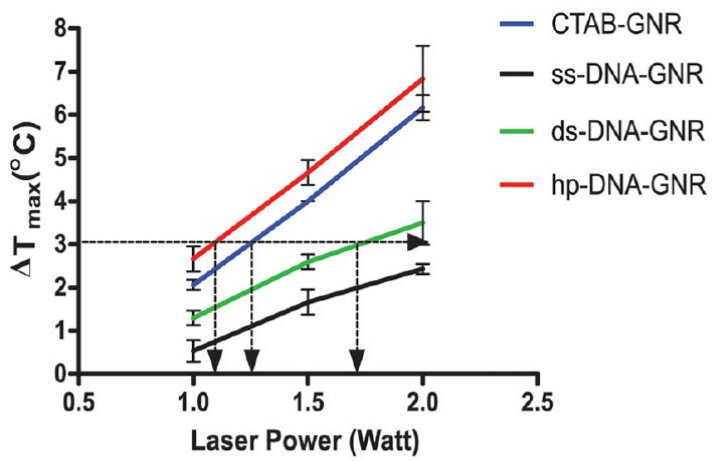

b $\quad \Delta \mathrm{T}_{\max }$ vs Time $(1.5 \mathrm{~W}, 300 \mu \mathrm{g} / \mathrm{ml})$

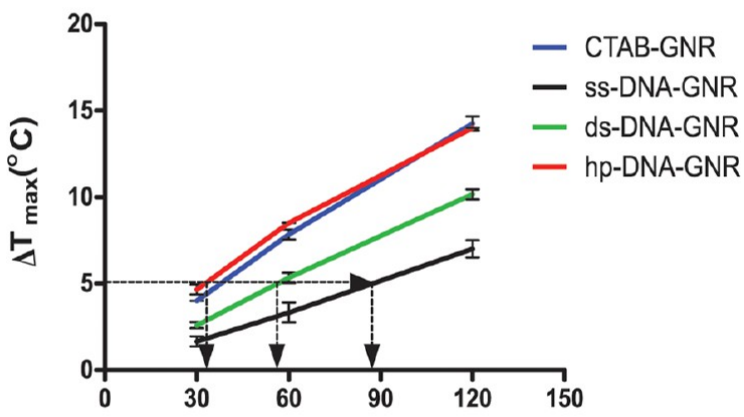

Time (Second)

C

$$
\Delta T_{\max } \text { vs Conc. }(1.5 \mathrm{~W}, 60 \mathrm{~s})
$$

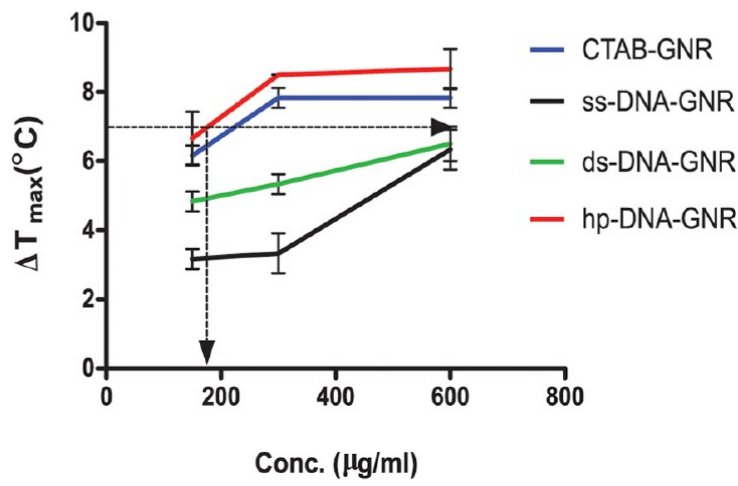

Figure 5. Estimation of the photothermal effect of the GNR conjugates. Representative plots for in vitro heating of CTAB as well as ss-, ds-, and hp-DNA-coated GNR suspensions. (a) Laser power-dependent photothermal effect demonstrated a linear relation in all cases. (b) Irradiation time-dependent heating of all conjugates also demonstrated linear relation. (c) Concentration-dependent hyperthermia effect demonstrated nonlinear relation for all GNR samples except ds-DNA-GNR. The error bars represent standard deviation of three independent experimental data sets in all cases.

DNA-functionalized GNR were incubated in phosphatebuffered saline (PBS) $(\mathrm{pH}-7.4)$ at $37{ }^{\circ} \mathrm{C}$ for 6,18 , and 24 h. Suspensions were then centrifuged, supernatants were collected, and pellets were resuspended in same volume of PBS, followed by UV-vis scanning to investigate any DNA release, including the effect on NIR absorbance. Results are depicted in Figure 6. While CTAB-capped GNR showed a drastically reduced absorbance band in the NIR region, hp-

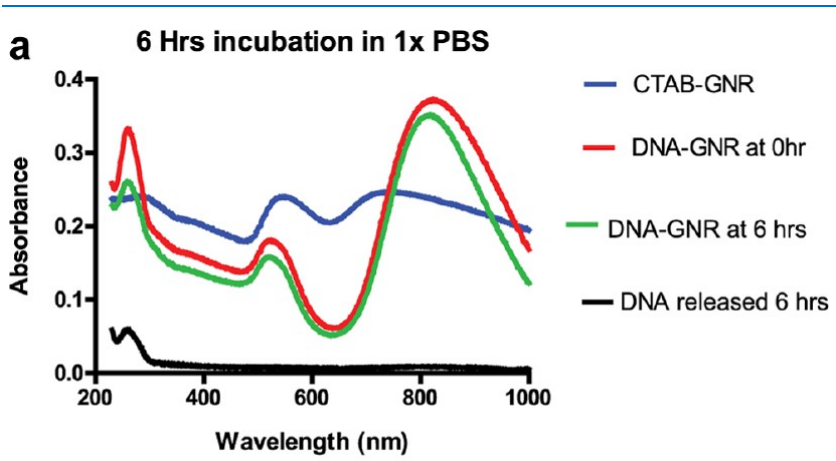

b 18 Hrs incubation in 1x PBS

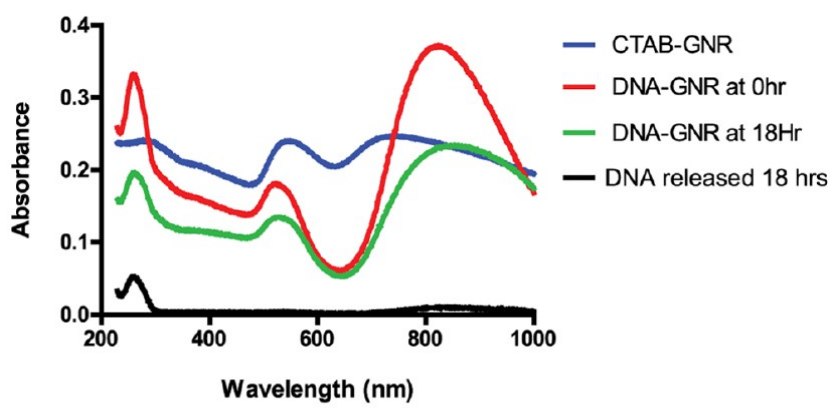

c $24 \mathrm{Hrs}$ incubation in 1x PBS

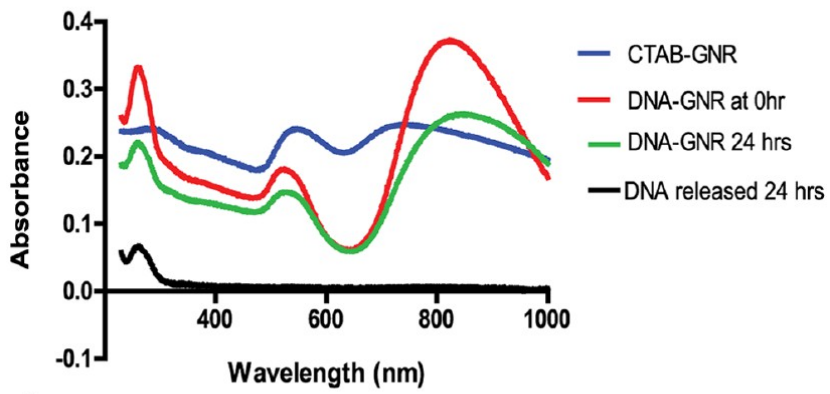

d

\begin{tabular}{|l|c|c|c|c|}
\hline & $\begin{array}{c}\text { Net Abs } \\
\text { DNonm } \\
\text { DNA-GNR }\end{array}$ & \% DNA on GNR & $\begin{array}{c}\text { Net Abs } 260 \mathrm{~nm} \\
\text { Supernatant }\end{array}$ & \% DNA released \\
\hline $0 \mathrm{hrs}$ & 0.13 & 100 & - & - \\
\hline $6 \mathrm{hrs}$ & 0.08 & 61.5 & 0.05 & 38.5 \\
\hline $18 \mathrm{hrs}$ & 0.07 & 54 & 0.052 & 40 \\
\hline $24 \mathrm{hrs}$ & 0.06 & 46 & 0.067 & 51.5 \\
\hline
\end{tabular}

Figure 6. Estimation of stability of the hp-DNA-GNR conjugate in biologically relevant conditions in vitro. UV-vis spectra of the hpDNA-conjugated GNR, incubated in PBS for (a) 6, (b) 18, and (c) 24 h. Results are summarized in (d).

DNA-GNR conjugate exhibited its characteristic NIR band at $812 \mathrm{~nm}$. Incubation for $6 \mathrm{~h}$ in the PBS at $37{ }^{\circ} \mathrm{C}$ caused little reduction in the NIR absorbance and $38.5 \%$ DNA release, in comparison to the freshly suspended hp-DNA-GNR (Figure $6 \mathrm{a}, \mathrm{d})$. Incubation for $18 \mathrm{~h}$ in a similar condition reduced NIR absorbance to half and caused 40\% DNA release, while $24 \mathrm{~h}$ incubation caused no further reduction in NIR absorbance but increased the DNA release to $51.5 \%$ (Figure $6 \mathrm{~b}-\mathrm{d}$ ).

Cellular Uptake of GNR Conjugates and Cytotoxicity in Combination with FdU-Hairpin. Although previous 

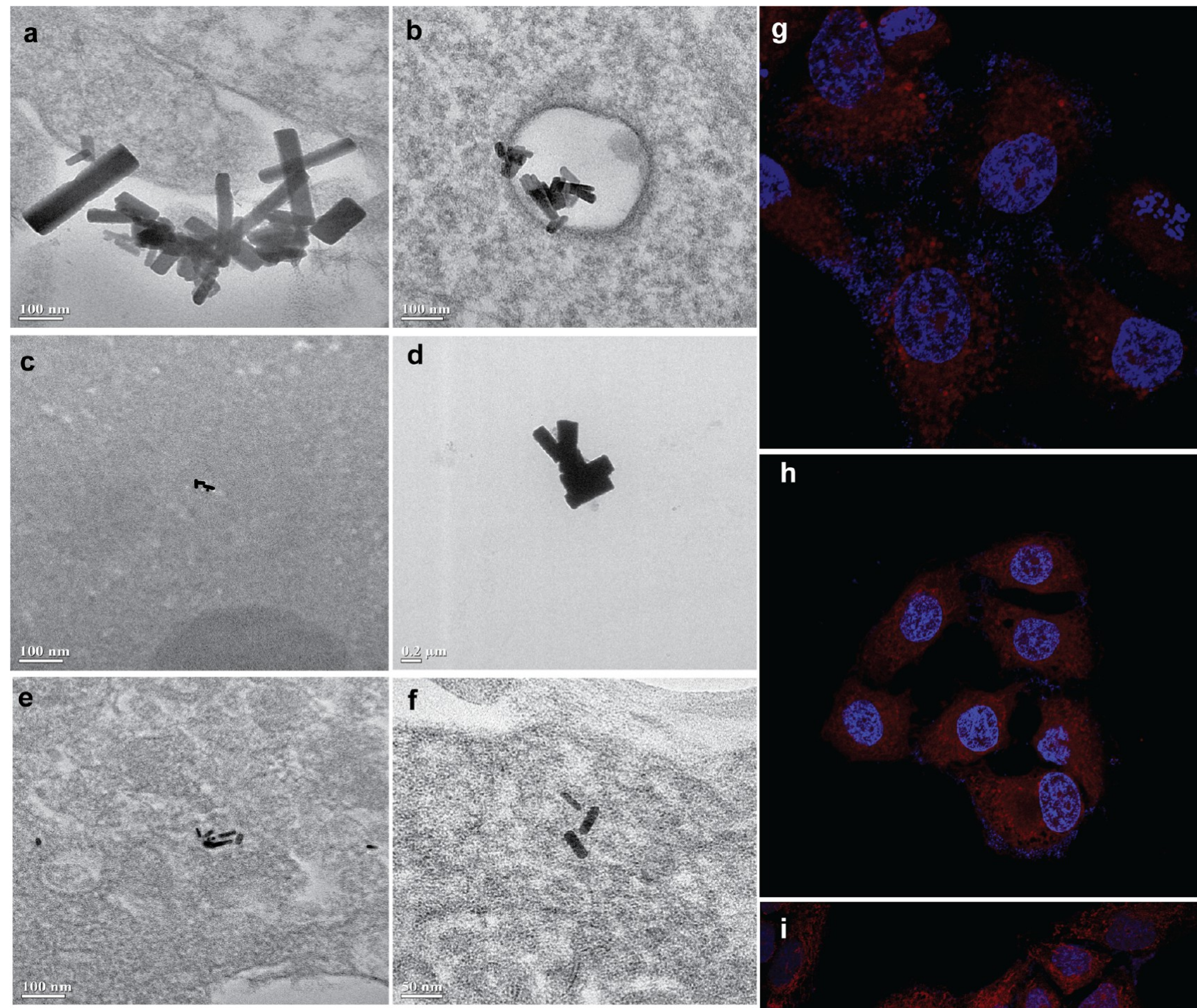

h
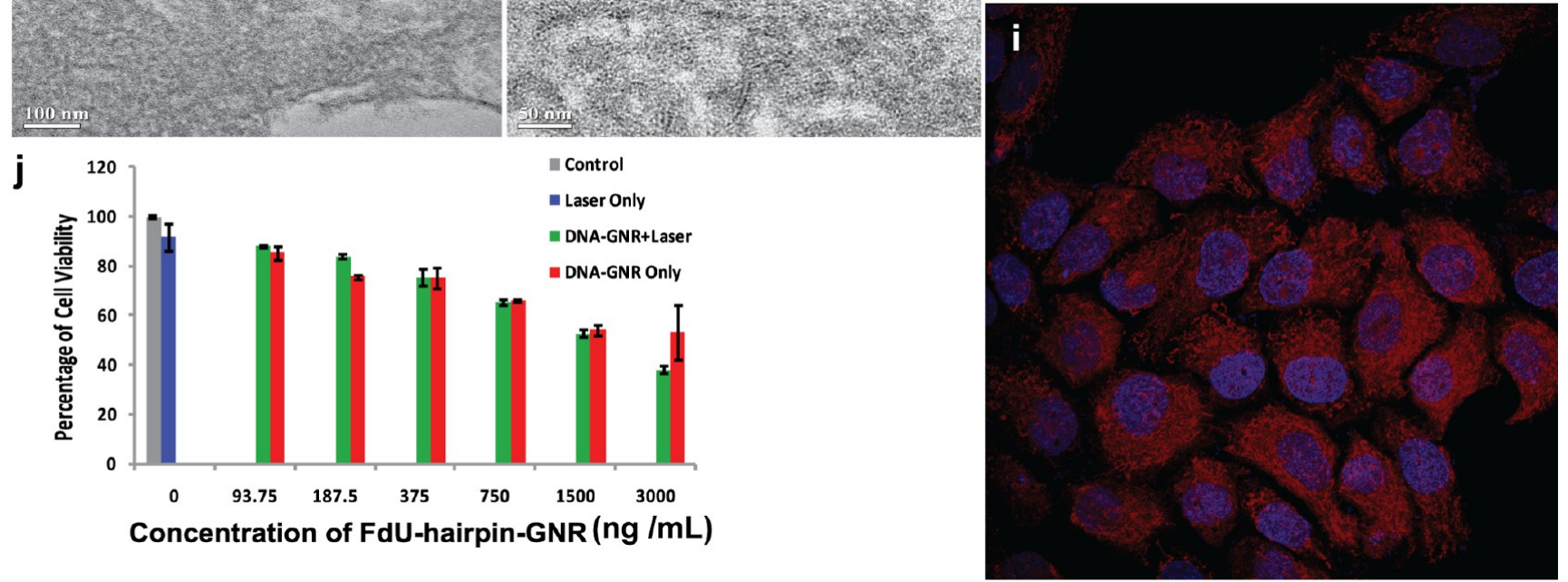

Figure 7. Investigation of cellular uptake and dispersion of GNR conjugates and cytotoxicity in combination with FdU-hairpin. (a) TEM images of ss-DNA-GNR-treated KB cells, with larger aggregates remaining outside the cell and (b) smaller aggregates inside the cell in a vesicular structure. (c) Region of the intracellular space containing ds-DNA-GNR conjugates and a portion of the nucleus. (d) A large portion of the bigger ds-DNAGNR aggregates remaining outside the cell. (e) TEM images of the hp-DNA-GNR in the intracellular space providing a larger view and (f) closer view of hp-DNA-functionalized GNR, demonstrating their dispersion in the intracellular environment. (g) Representative confocal image of cells treated with Cy5-labeled ss-DNA-GNR (red), including nuclear demarcation by 4',6-diamidino-2-phenylindole (DAPI) (blue), demonstrating cellular uptake of the conjugates. (h) Confocal image of cells treated with Cy5-labeled ds-DNA-GNR (red), followed by DAPI staining (blue), demonstrating intracellular delivery of the conjugate. (i) Image of cells treated with Cy5-labeled hp-DNA-GNR (red), followed by DAPI staining (blue), demonstrating efficient intracellular uptake of the conjugate. (j) Graphical representation of cell viability assay results, demonstrating the cytotoxicity of FdU-hairpin-coated GNR in a dose-dependent manner. Cytotoxicity is further enhanced with NIR laser irradiation in the highest concentration. The error bars in all cases represent the standard deviation of three independent experimental data sets. 
studies demonstrated intracellular uptake of DNA-functionalized GNR for gene delivery, none of these studies investigated dispersion of the conjugates in the cellular environment by high-resolution microscopy. Dispersions of ss-, ds-, and hp-DNA-coated GNR were studied in KB cell line under standard tissue culture conditions. ss-DNA-GNR conjugates are found in the aggregated state (Figure $7 \mathrm{a}, \mathrm{b}$ ); larger aggregates remained outside the cell adjacent to the plasma membrane (Figure 7a), while small agglomerates were transported inside (Figure 7b). A large fraction of the ds-DNAGNR conjugates formed bigger aggregates and are found outside the cell (Figure $7 \mathrm{~d}$ ), and only a small portion went inside (Figure 7c). In contrast, no aggregation was observed in the case of hp-DNA-GNR and discrete monodispersed GNR conjugates were found inside the cell (Figure 7e,f). Intracellular uptakes of all DNA-conjugated GNR samples were further investigated with confocal microscopy, using Cy5labeled DNA versions. Figure $7 \mathrm{~g}-\mathrm{i}$ and S9 (Supporting Information) demonstrate intracellular uptake of all conjugates, while hp-DNA-GNR-treated cells showed relatively higher Cy5 fluorescence.

FdU-containing DNA hairpin was conjugated with GNR and investigated on $\mathrm{KB}$ cells to evaluate the cytotoxic activity of the conjugates with and without NIR radiation. The results are depicted in Figure 7j. As evident from the data, the FdUhairpin-coated GNR demonstrated cytotoxicity toward $\mathrm{KB}$ cells in a dose-dependent manner, at concentrations ranging from 93.75 to $3000 \mathrm{ng} / \mathrm{mL}$, which corresponds to $3-96 \mathrm{nM}$ in terms of FdU-hairpin concentration. ${ }^{32-34}$ NIR irradiation demonstrated some effect on the cytotoxic activity of the conjugate, especially at the maximum concentration tested. Maximum cytotoxicity is observed at the highest concentrations, with $3000 \mathrm{ng} / \mathrm{mL}$ GNR and $96 \mathrm{nM}$ FdU-hairpin; almost $62 \%$ cells were killed in combination with NIR irradiation, while FdU-hairpin-GNR alone killed $\sim 47 \%$ cells.

\section{CONCLUSIONS}

In the present study, we systematically investigated the effects of DNA secondary structures on GNR physicochemical and biological properties. We also standardized a method for successfully exchanging overall GNR surface coating with maximum number of DNA molecules thus far reported. $5,22,24$ This is the first time that ss-, ds-, and hp-DNA structures have all been conjugated to GNR under identical conditions and evaluated in terms of dispersion, conjugation efficiency, photothermal potential, and biocompatibility. Our studies show that ds- and ss-DNA structures are relatively less efficient for conjugation with GNR and they induce aggregation and reduce the photothermal effect. A large fraction of the aggregated ss-DNA-GNR as well as ds-DNA-GNR remained outside the cell, while smaller aggregates become internalized. Intracellular delivery of the conjugates in the aggregated condition could be useful for experimental purposes, delivering genes and other suitable agents, but might not be promising for future clinical applications. ${ }^{22,26,35,36}$ In contrast, hairpin DNA structures are most efficient for conjugation with the GNR surface and produce highly dispersed nanoconjugates, demonstrating maximum photothermal effect, and stable under biologically relevant conditions. hp-DNA-GNR conjugates are suitable for carrying cytotoxic nucleotides in a large amount inside the cell and they remain dispersed in the cellular environment. Therefore, hairpin could be a very promising structure for oligonucleotide-based therapeutics delivery via GNR and suitable for multimodality applications.

\section{EXPERIMENTAL SECTION}

Synthesis of Gold Nanorods. Gold nanorod was synthesized following the previously published works by Megan et al. ${ }^{37}$ and Jana., N. R. ${ }^{38}$ The growth solution was prepared at $25-30{ }^{\circ} \mathrm{C}$. $\mathrm{HAuCl}_{4}(200 \mu \mathrm{L}, 100 \mathrm{mM})$ was added to $40 \mathrm{~mL}$ of $\mathrm{CTAB}(100 \mathrm{mM})$ and mixed thoroughly by pipetting, followed by addition of $40 \mu \mathrm{L}$ of $\mathrm{AgNO}_{3}(100 \mathrm{mM})$, and the solution was gently mixed by inverting the tube. Then, $44 \mu \mathrm{L}$ of $37 \% \mathrm{HCl}$ was introduced to the solution, followed by addition of $360 \mu \mathrm{L}$ of ascorbic acid $(100 \mathrm{mM})$, and mixed gently until the solution became colorless. Immediately afterward, $50 \mu \mathrm{L}$ of ice-cold $\mathrm{NaBH}_{4}$ solution $(2 \mathrm{mM}$ ) was added to the unstirred growth solution and allowed to react overnight. $^{38,39}$ The resulting gold nanorods had dimensions of $30.0( \pm 5) \mathrm{nm} \times 10.0( \pm 1) \mathrm{nm}$ and absorbance maxima at about $800-810 \mathrm{~nm}$. The GNR size distribution was confirmed by transmission electron microscopy (Figure S5a, Supporting Information). A standard curve of concentration versus absorbance at $\lambda_{\max }(808 \mathrm{~nm})$ was prepared to determine the concentration of the GNR stock for different batches of synthesis (Figure S5b, Supporting Information).

Conjugation of DNA-GNR. For the process of conjugation of different DNA secondary structures on GNR surface, we used thiolated versions of single-stranded 10-mer of thimidine $\left(\mathrm{T}_{10}\right)$ as ss-DNA and consecutive $10 \mathrm{~A}-\mathrm{T}$ base pairs $(\mathrm{A}-\mathrm{T})_{10}$ as ds-DNA, and a hairpin DNA sequence consists of a 10-basepairs stem with all $\mathrm{A}-\mathrm{T}$ base pairing and a CGAAG loop as hp-DNA $^{33,40}$ (Figure S10, Supporting Information). For the evaluation of anticancer activity of the nanoconjugate, we used cytotoxic nucleotide-containing DNA hairpin, where 10 consecutive thymine were substituted with FdU nucleobases. $^{33,40}$ For confocal microscopy, Cy5-labeled DNA molecules were used. Native gel electrophoresis, as described in the previous studies, confirmed discrete intramolecular DNA hairpin formation. ${ }^{33}$ Conventional nucleotide-containing thiolated DNA sequences were supplied by GCC Biotech India Pvt. Ltd., and all FdU-containing thiolated DNA sequences were supplied by the Wake Forest University Health Sciences. All thiolated DNA sequences were purified twice by gelfiltration chromatography using a Sephadex G-25 column with high-performance liquid chromatography (HPLC)-grade water. All of the reactions were carried out in HPLC-grade water, as well.

For the preparation of $1 \mathrm{~mL}$ of each DNA-GNR suspension, $1 \mathrm{~mL}$ of CTAB-coated GNR suspension (GNR concentration, $300 \mu \mathrm{g} / \mathrm{mL}$ ) was washed by centrifugation at $15000 \mathrm{~g}$ for 30 min at $30{ }^{\circ} \mathrm{C}$. A $95 \%$ supernatant was discarded, and the GNR pellet was resuspended in $1 \mathrm{~mL}$ of HPLC water by sonication and vortexing. The washing step was repeated again, the final GNR pellet was resuspended in $10 \%$ of the initial volume, i.e., $100 \mu \mathrm{L}$ of water. ${ }^{41}$ This GNR suspension was kept in $4-8{ }^{\circ} \mathrm{C}$ for 30 min before adding DNA to it. All of the hp-, ds-, and ssDNA stock solutions were prepared in HPLC-grade water at a concentration of $100 \mu \mathrm{M}$. Monomeric hp-DNA and ds-DNA were prepared by heating DNA solutions at $85^{\circ} \mathrm{C}$ for $5 \mathrm{~min}$, followed by rapid cooling in ice. DNA molecules were conjugated on the GNR surface by adding $12 \mathrm{nmol}$ of each ice-cold DNA solution in cold GNR suspensions, as prepared above after washing (final DNA concentration, $12 \mu \mathrm{M}$ ). DNA addition was done in ice, and the volume was adjusted with 
ice-cold water to $1 \mathrm{~mL}$. The DNA-GNR suspensions were mixed slowly and carefully by pipetting one to two times. After DNA addition and mixing, the suspensions were transferred to room temperature $\left(25-30{ }^{\circ} \mathrm{C}\right)$ and incubated for $48 \mathrm{~h}$ at static condition. For efficient DNA conjugation, the key point is keeping GNR particles in dispersed monomeric condition while removing $\mathrm{CTAB}$ to its minimum required concentration. Efficient removal of $\mathrm{CTAB}$, keeping GNRs monomeric, is possible by efficiently washing salt from the GNR suspension and keeping the suspension at cold after second wash, which significantly reduce CTAB dissociation from GNR surface, while keeping very little $\mathrm{CTAB}$ free in the suspension. Efficient removal of salt from DNA solution is also very important as it can cause GNR aggregation during conjugation. In salt-free condition, most likely CTAB dissociates slowly, providing opportunity to the thiolated DNA molecules for conjugation. Since $\mathrm{Au}-\mathrm{S}$ has a relatively stronger interaction with its partially covalent character, it remains stable after formation at room temperature, without providing further opportunity to $\mathrm{CTAB}$ molecules for interaction with GNR. For all in vitro experiments, a control CTAB-GNR suspension was included after removal of excess CTAB and HPLC water was added in place of DNA. The color of the DNA-GNR suspensions changed gradually after DNA addition. After $48 \mathrm{~h}$ of incubation at room temperature, the DNA-GNR suspensions were centrifuged at $10000 \mathrm{~g}$ for $1 \mathrm{~h}$ at $4{ }^{\circ} \mathrm{C}$ to remove unconjugated DNA, the supernatants were collected and scanned to determine the amount of unbound DNA, and the pellets were resuspended in equal volume of water by brief sonication for 2-3 s (Figure S3, Supporting Information). The formation of DNA-GNR conjugates was evaluated by UV-vis spectroscopy. The characteristic absorbance of DNA around $260 \mathrm{~nm}$ and characteristic NIR band were monitored.

Spectroscopic Characterization of DNA-GNR Conjugates. UV-vis spectra were acquired under ambient conditions using a TECAN infinite M 200 PRO spectrophotometer; hp-, ds-, and ss-DNA-conjugated GNR suspensions along with CTAB-capped GNR were scanned at the rate of 1 $\mathrm{nm} / \mathrm{s}$, over the range of $230-1000 \mathrm{~nm}$ using a quartz cuvette of $1 \mathrm{~cm}$ path length. $\zeta$ potential values of the conjugates were measured at ambient conditions using a Malvern Zetasizer $S$ spectrophotometer with a compatible cuvette. For Raman spectroscopy, $10 \mu \mathrm{L}$ of each DNA-conjugated GNR and CTAB-GNR samples were placed on a glass slide and allowed to dry in static condition at room temperature. Raman spectra were recorded using a LabRAM HR (Jobin Yvon) spectrometer equipped with an air-cooled $785 \mathrm{~nm}$ laser source and a Peltier-cooled charge-coupled device detector. ${ }^{42}$ The laser beam from the Raman spectrometer was focused onto the sample through a $100 \times$ microscope objective with a numerical aperture of 0.9 and scanned over the region $100-3000 \mathrm{~cm}^{-1}$. For FTIR spectra, $1200 \mu \mathrm{L}$ of each sample was centrifuged at $20000 \mathrm{~g}$ for $1 \mathrm{~h}$ at $4{ }^{\circ} \mathrm{C}$ and the supernatant was removed completely. Then, the pellets were resuspended in $20 \mu \mathrm{L}$ of deuterium oxide $\left(\mathrm{D}_{2} \mathrm{O}\right)$; a nonthiolated hp-DNA dissolved in $\mathrm{D}_{2} \mathrm{O}$ with a concentration $12 \mu \mathrm{M}$ was used as a DNA-only control along with CTAB-GNR; and all of the samples were scanned over the range of $1000-4000 \mathrm{~cm}^{-1}$ with a PerkinElmer Spectrum 1000 spectrophotometer, using a liquid sample holder. $\mathrm{D}_{2} \mathrm{O}$ was used to avoid any interference from $\mathrm{H}_{2} \mathrm{O}$, especially in the region $2700-4000 \mathrm{~cm}^{-1}$. 43

Microscopic Characterization of DNA-GNR Conjugates. For TEM imaging and chemical mapping by STEM-
EDX, the GNR conjugates were diluted 10 times; $10 \mu \mathrm{L}$ of each diluted suspension was placed on a carbon-coated 300 mesh copper grid and incubated for $15 \mathrm{~min}$ at room temperature; and then air-dried under the same condition. The samples were visualized under a JEOL JEM 2100F transmission electron microscope using a $200 \mathrm{kV}$ accelerating voltage. ${ }^{44}$ Chemical mapping was done in the STEM mode of the same instrument under similar condition.

In Vitro Heating of DNA-GNR Conjugates. The heat emitted by GNR conjugates upon NIR irradiation was evaluated by measuring the change in temperature of their aqueous suspensions with a mercury thermometer. GNR suspensions $(1 \mathrm{~mL})$ were placed in sealed NIR-transparent glass cuvettes fitted with a thermometer. The sample was then irradiated by an $808 \mathrm{~nm}$ laser beam using a CNI Laser MDLIII 808 (FC) laser system with power levels of 1.0, 1.5, and 2.0 $\mathrm{W}$ for durations of 30,60 , or $120 \mathrm{~s}$. The initial temperature of each solution was recorded prior to irradiation, and the maximum temperature was recorded postirradiation. ${ }^{13}$ The net temperature increase was estimated by subtracting the heating of pure water in similar conditions.

Evaluation of Stability of hp-DNA-GNR Conjugates at Physiological Conditions. After conjugation, $1000 \mu \mathrm{L}$ of hpDNA and CTAB-coated GNR suspensions were centrifuged at $10000 \mathrm{~g}$ for $1 \mathrm{~h}$ at $4{ }^{\circ} \mathrm{C}$ and the pellets were resuspended in $1 \times$ PBS. GNR suspensions were incubated at $37^{\circ} \mathrm{C}$ for $0,6,18$, and $24 \mathrm{~h} ; 250 \mu \mathrm{L}$ of each sample of different time points were collected and centrifuged at $10000 \mathrm{~g}$ for $1 \mathrm{~h}$ at $25{ }^{\circ} \mathrm{C}$. The supernatants were collected and the pellets were resuspended in the same volume of $1 \times$ PBS by brief sonication. All GNR samples and the corresponding supernatants were scanned with a UV-vis spectrophotometer over a range of 230-1000 $\mathrm{nm}$ to detect DNA released in the supernatant over time as well as change in NIR absorbance.

Study of Intracellular Dispersion of DNA-GNR Conjugates. All tissue culture experiments were performed on human cervical cancer cells ( $\mathrm{KB}$ cell line). The cell line was gifted by Dr. Chinmay Kumar Panda, Chittaranjan National Cancer Institute, Kolkata, India. The cells were grown in highglucose Dulbecco's modified Eagle's medium, supplemented with $15 \%$ heat-inactivated fetal bovine serum (FBS) and 1.5\% pen-strep-glutamine (Gibco, reference no. 10378-016, 100 $\mathrm{mL}$ ) in a humid atmosphere maintained at $37{ }^{\circ} \mathrm{C}$ with $5 \%$ $\mathrm{CO}_{2}$. The cells were seeded in $90 \mathrm{~mm}$ plates at a cell density of $10^{6}$ cells/plate with $6 \mathrm{~mL}$ of complete medium. After $24 \mathrm{~h}$, the medium was removed and the cells were washed with $2 \mathrm{~mL}$ of PBS, followed by addition of complete medium containing 3 $\mu \mathrm{g} / \mathrm{mL}$ of hp-, ds-, or ss-DNA-coated GNR. After $24 \mathrm{~h}$ of incubation, the medium was removed and the cells were washed with $1 \mathrm{~mL}$ of chilled $3 \%$ glutaraldehyde fixative solution in phosphate buffer. The fixative solution $(1 \mathrm{~mL})$ was added again in each plate and kept at $4{ }^{\circ} \mathrm{C}$ for $5 \mathrm{~min}$, followed by incubation at room temperature $\left(25-30^{\circ} \mathrm{C}\right)$ for $1 \mathrm{~h} .{ }^{45,46}$ Then, the cells were scraped carefully from the plates using a scraper and centrifuged at $1500 \mathrm{rpm}$ for $5 \mathrm{~min}$. The supernatant was removed and the cell pellet was resuspended in $1 \mathrm{~mL}$ of ice-cold fresh fixative solution. The cells were again centrifuged at $1500 \mathrm{rpm}$ for $5 \mathrm{~min}$ before secondary fixation and washed with PBS. Secondary fixation was done by incubating the cells in osmium tetroxide for $1 \mathrm{~h}$ at $4{ }^{\circ} \mathrm{C}$, followed by washing with PBS. Cell dehydration, embedding, tissue sectioning, and staining for TEM were done following the standard protocol. ${ }^{47-49}$ Tissue sections were loaded on 300 
mesh copper grid and investigated under a JEOL JEM-100CX II transmission electron microscope at $120 \mathrm{kV}$ under variable magnifications.

Determination of Cellular Uptake of DNA-GNR Conjugates. To investigate the cellular uptake of the complex, Cy5-labeled versions of the thiolated DNA samples were used for conjugation; cell nuclei were stained with DAPI after fixation and intracellular fluorescence of Cy5 and DAPI was investigated. The cells were grown on coverslips at a cell density $10000 / 0.5 \mathrm{~mL}$ complete medium for $24 \mathrm{~h}$ and then treated with complete medium containing nanoconjugates of concentration $3.0 \mu \mathrm{g} / \mathrm{mL}$ and incubated for $18 \mathrm{~h}$. At the end of incubation, the cells were washed with cold PBS and fixed with $3 \%$ glutaraldehyde for $2 \mathrm{~h}$ at $4{ }^{\circ} \mathrm{C}$, followed by washing with PBS three times. DAPI (Thermo Fisher Scientific, product no. 62248 ) staining solution of $1 \mu \mathrm{g} / \mathrm{mL}$ was prepared in PBS and added on the coverslips, followed by incubation at room temperature $\left(25-30{ }^{\circ} \mathrm{C}\right)$ for $1 \mathrm{~min}$. After incubation, excess DAPI stain was removed by washing with PBS for three times. ${ }^{50}$ The coverslips were mounted onto glass slides using ProLong Diamond Antifade Mountant (Thermo Fisher Scientific, reference no. P36970). Then, the slides were incubated at room temperature for $3 \mathrm{~h}$, protected from light, and investigated under a confocal microscope (Leica TCS SP8) using the imaging software Leica Application Suite. The images were overlaid using ImageJ 1.46 software. ${ }^{51}$

Determination of Cytotoxicity of FdU-Hairpin-GNR Conjugates in vitro. For the experiment, FdU-containing DNA hairpin was used in conjugation with GNR. The cytotoxicity of the FdU-hairpin-GNR conjugate was determined using a cell viability assay with 3-(4,5-dimethylthiazol-2yl)-2,5-diphenyltetrazolium bromide (MTT) readout. DNAGNR was prepared and sterilized with filtration through a 0.2 $\mu \mathrm{m}$ sterile filter; after filtration, the concentration was $\sim 300$ $\mu \mathrm{g} / \mathrm{mL}$. The cells were seeded in a 48 -well plate at a cell density of 5000 cells/well with $250 \mu \mathrm{L}$ of complete medium. After $24 \mathrm{~h}$, the medium was removed and the cells were washed twice with $500 \mu \mathrm{L}$ of PBS, followed by addition of complete medium containing varying concentrations of the nanoconjugate. The final GNR concentrations of the conjugate were $93.75,187.5,375,750,1500$, and $3000 \mathrm{ng} / \mathrm{mL}$ corresponding to $3,6,12,24,48$, and $96 \mathrm{nM}$ FdU-hairpin concentrations. The media of wells assigned for control and laser only were replaced with fresh complete media and incubated overnight. After $24 \mathrm{~h}$, the cells were washed with 500 $\mu \mathrm{L}$ of PBS, followed by addition of fresh media. Wells assigned for laser-only and DNA-GNR + laser treatment were irradiated with a $808 \mathrm{~nm}$ laser at a power density of $0.85 \mathrm{~W} / \mathrm{cm}^{2}$ for $60 \mathrm{~s}$ and incubated at $37{ }^{\circ} \mathrm{C}$ for $24 \mathrm{~h}$. After incubation, $62.5 \mu \mathrm{L}$ of $1.2 \mathrm{mg} / \mathrm{mL}$ MTT reagent prepared in sterile water (Amresco, product no. 0646C193) was added and incubated for $4 \mathrm{~h}$ at 37 ${ }^{\circ} \mathrm{C}$ in the dark. After that, the plate was centrifuged at 1000 $\mathrm{rpm}$ for $10 \mathrm{~min}$ at $4{ }^{\circ} \mathrm{C}$. After centrifugation, $220 \mu \mathrm{L}$ of the supernatant was discarded from each well and the formazan crystals were dissolved in equal volume of dimethyl sulfoxide by pipetting. Absorbance of the formazan complex at $540 \mathrm{~nm}$ was measured using a Tecan Infinite M 200 PRO plate reader. Each set of data (net absorbance) was then expressed as percentage, considering the control group as $100 \%$ survival.

\section{ASSOCIATED CONTENT}

\section{S Supporting Information}

The Supporting Information is available free of charge on the ACS Publications website at DOI: 10.1021/acsomega.8b00969.

Complete FTIR spectra of GNR conjugates; highresolution TEM images of GNR conjugates; pictorial representation of GNR suspensions with different surface modifications; images of chemical mapping of GNR conjugates with footprint of bromine, including STEM images; TEM image of CTAB-GNR, standard curve of GNR, and mathematical calculations to estimate the number of hp-DNA molecules per GNR; graphical representations of laser power, irradiation time, and concentration-dependent temperature increase of the GNR conjugates; confocal microscopy images of human cervical cancer cells treated with Cy5-labeled DNAGNR; schematic diagram of DNA molecules used in the study; and details of materials used for the study (PDF)

\section{AUTHOR INFORMATION}

\section{Corresponding Author}

*E-mail: supratimghos@gmail.com. Phone: +91-33-24765101 (ext 329). Fax: 91-33-2475-7606.

ORCID ${ }^{\circ}$

Supratim Ghosh: 0000-0003-1552-0538

Notes

The authors declare no competing financial interest.

\section{ACKNOWLEDGMENTS}

This study was supported by the Department of Science and Technology, Govt. of India, under INSPIRE Faculty Award, [IFA-13, LSBM-55]. The authors thank Dr. Dipten Bhattacharya, CSIR-CGCRI, for his support and inspiration for the study; Dr. Chinmay Kumar Panda, CNCI, for providing the KB cell line; and Dr. Prasenjit Saha, CNCI, for sharing their tissue culture facility. They sincerely thank Dr. Achintya Singha and Shib Shankar Singha for helping them with the acquisition of the Raman spectra. The authors acknowledge Bose Institute, Kolkata, for helping with the confocal microscopy and FTIR spectroscopy, and the Indian Institute of Technology, Kharagpur, for helping with the high-resolution TEM and chemical mapping. The authors also acknowledge the SAIF, North-Eastern Hill University, for helping with the processing and investigation of the cellular samples by TEM.

\section{REFERENCES}

(1) Zhan, P.; et al. Reconfigurable Three-Dimensional Gold Nanorod Plasmonic Nanostructures Organized on DNA Origami Tripod. ACS Nano 2017, 1172-1179.

(2) Han, M. S.; Lytton-Jean, A. K. R.; Mirkin, C. A. A Gold Nanoparticle Based Approach for Screening Triplex DNA Binders. J. Am. Chem. Soc. 2006, 4954-4955.

(3) Crouse, H. F.; Doudt, A.; Zerbe, C.; Basu, S. Detection of Quadruplex DNA by Gold Nanoparticles. J. Anal. Methods Chem. 2012, 2012, No. 327603.

(4) Cheng, S.; Zheng, B.; Wang, M.; Ge, X.; Zhao, Q.; Liu, W.; Lam, M. H. The Unfolding of G-Quadruplexes and Its Adverse Effect on DNA-Gold Nanoparticles-Based Sensing System. Biosens. Bioelectron. 2014, 53, 479-485.

(5) Wei, G.; Yu, J.; Wang, J.; Gu, P.; Birch, D. J. S.; Chen, Y. Hairpin DNA-Functionalized Gold Nanorods for MRNA Detection in Homogenous Solution. J. Biomed. Opt. 2016, 21, No. 097001. 
(6) Du, Y.; Jiang, Q.; Beziere, N.; Song, L.; Zhang, Q.; Peng, D.; Chi, C.; Yang, X.; Guo, H.; Diot, G.; et al. DNA-Nanostructure-GoldNanorod Hybrids for Enhanced In Vivo Optoacoustic Imaging and Photothermal Therapy. Adv. Mater. 2016, 28, 10000-10007.

(7) Jin, H.; Liu, X.; Gui, R.; Wang, Z. Facile Synthesis of Gold Nanorods/Hydrogels Core/Shell Nanospheres for $\mathrm{PH}$ and nearInfrared-Light Induced Release of 5-Fluorouracil and ChemoPhotothermal Therapy. Colloids Surf., B 2015, 128, 498-505.

(8) He, X.; Wolkers, W. F.; Crowe, J. H.; Swanlund, D. J.; Bischof, J. C. In Situ Thermal Denaturation of Proteins in Dunning AT-1 Prostate Cancer Cells: Implication for Hyperthermic Cell Injury. Ann. Biomed. Eng. 2004, 32, 1384-1398.

(9) Huang, X.; Jain, P. K.; El-Sayed, I. H.; El-Sayed, M. A. Determination of the Minimum Temperature Required for Selective Photothermal Destruction of Cancer Cells with the Use of Immunotargeted Gold Nanoparticles. Photochem. Photobiol. 2006, 82, 412-417.

(10) Kobayashi, H.; Watanabe, R.; Choyke, P. L. Improving Conventional Enhanced Permeability and Retention (EPR) Effects; What Is the Appropriate Target? Theranostics 2013, 4, 81-89.

(11) Tong, X.; Wang, Z.; Sun, X.; Song, J.; Jacobson, O.; Niu, G.; Kiesewetter, D. O.; Chen, X. Size Dependent Kinetics of Gold Nanorods in EPR Mediated Tumor Delivery. Theranostics 2016, 6, 2039-2051.

(12) Huang, X.; El-Sayed, I. H.; Qian, W.; El-Sayed, M. A. Cancer Cell Imaging and Photothermal Therapy in the Near-Infrared Region by Using Gold Nanorods. J. Am. Chem. Soc. 2006, 128, 2115-2120.

(13) Ghosh, S.; Dutta, S.; Gomes, E.; Carroll, D.; D’Agostino, R.; Olson, J.; Guthold, M.; Gmeiner, W. H. Increased Heating Efficiency and Selective Thermal Ablation of Malignant Tissue with DNAEncased Multiwalled Carbon Nanotubes. ACS Nano 2009, 3, 26672673.

(14) Kostarelos, K. The Long and Short of Carbon Nanotube Toxicity. Nat. Biotechnol. 2008, 26, 774-776.

(15) Liu, Y.; Zhao, Y.; Sun, B.; Chen, C. Understanding the Toxicity of Carbon Nanotubes. Acc. Chem. Res. 2013, 46, 702-713.

(16) Gui, C.; Cui, D. Functionalized Gold Nanorods for Tumor Imaging and Targeted Therapy. Cancer Biol. Med. 2012, 9, 221-233.

(17) Ali, M. R. K.; Rahman, M. A.; Wu, Y.; Han, T.; Peng, X.; Mackey, M. A.; Wang, D.; Shin, H. J.; Chen, Z. G.; Xiao, H.; et al. Efficacy, Long-Term Toxicity, and Mechanistic Studies of Gold Nanorods Photothermal Therapy of Cancer in Xenograft Mice. Proc. Natl. Acad. Sci. U.S.A. 2017, 114, E3110-E3118.

(18) Alkilany, A. M.; Murphy, C. J. Toxicity and cellular uptake of gold nanoparticles: what we have learned so far? J. Nanopart. Res. 2010, 2313-2333.

(19) Isomaa, B.; Reuter, J.; Djupsund, B. M. The Subacute and Chronic Toxicity of Cetyltrimethylammonium Bromide (CTAB), a Cationic Surfactant, in the Rat. Arch. Toxicol. 1976, 35, 91-96.

(20) Wijaya, A.; Hamad-Schifferli, K. Ligand Customization and DNA Functionalization of Gold Nanorods via Round-Trip Phase Transfer Ligand Exchange. Langmuir 2008, 24, 9966-9969.

(21) Gole, A.; Murphy, C. J. Biotin-Streptavidin-Induced Aggregation of Gold Nanorods: Tuning Rod-Rod Orientation. Langmuir 2005, 21, 10756-10762.

(22) Chen, C.-C.; Lin, Y.-P.; Wang, C.-W.; Tzeng, H.-C.; Wu, C.-H.; Chen, Y.-C.; Chen, C.-P.; Chen, L.-C.; Wu, Y.-C. DNA-Gold Nanorod Conjugates for Remote Control of Localized Gene Expression by near Infrared Irradiation. J. Am. Chem. Soc. 2006, 128, 3709-3715.

(23) Pal, S.; Deng, Z.; Wang, H.; Zou, S.; Liu, Y.; Yan, H. DNA Directed Self-Assembly of Anisotropic Plasmonic Nanostructures. J. Am. Chem. Soc. 2011, 133, 17606-17609.

(24) Shi, D.; Song, C.; Jiang, Q.; Wang, Z.-G.; Ding, B. A Facile and Efficient Method to Modify Gold Nanorods with Thiolated DNA at a Low PH Value. Chem. Commun. 2013, 49, 2533-2535.

(25) Pekcevik, I. C.; Poon, L. C. H.; Wang, M. C. P.; Gates, B. D. Tunable Loading of Single-Stranded DNA on Gold Nanorods through the Displacement of Polyvinylpyrrolidone. Anal. Chem. 2013, 85, 9960-9967.

(26) Wijaya, A.; Schaffer, S. B.; Pallares, I. G.; Hamad-Schifferli, K. Selective Release of Multiple DNA Oligonucleotides from Gold Nanorods. ACS Nano 2009, 3, 80-86.

(27) Patil, S.; Sandberg, A.; Heckert, E.; Self, W.; Seal, S. Protein Adsorption and Cellular Uptake of Cerium Oxide Nanoparticles as a Function of Zeta Potential. Biomaterials 2007, 28, 4600-4607.

(28) Pan, B.; Cui, D.; Ozkan, C.; Xu, P.; Huang, T.; Li, Q.; Chen, H.; Liu, F.; Gao, F.; He, R. DNA-Templated Ordered Array of Gold Nanorods in One and Two Dimensions. J. Phys. Chem. C 2007, 111, 12572-12576.

(29) Pawlukojć, A.; Leciejewicz, J.; Ramirez-Cuesta, A. J.; NowickaScheibe, J. L-Cysteine: Neutron Spectroscopy, Raman, IR and Ab Initio Study. Spectrochim. Acta, Part A 2005, 61, 2474-2481.

(30) Saute, B.; Premasiri, R.; Ziegler, L.; Narayanan, R. Gold Nanorods as Surface Enhanced Raman Spectroscopy Substrates for Sensitive and Selective Detection of Ultra-Low Levels of Dithiocarbamate Pesticides. Analyst 2012, 137, 5082-5087.

(31) Devi, S.; Singh, B.; Paul, A. K.; Tyagi, S. Highly Sensitive and Selective Detection of Trinitrotoluene Using Cysteine-Capped Gold Nanoparticles. Anal. Methods 2016, 8, 4398-4405.

(32) Liao, Z.-Y.; Sordet, O.; Zhang, H.-L.; Kohlhagen, G.; Antony, S.; Gmeiner, W. H.; Pommier, Y. A Novel Polypyrimidine Antitumor Agent FdUMP [10] Induces Thymineless Death with Topoisomerase I-DNA Complexes. Cancer Res. 2005, 65, 4844-4851.

(33) Ghosh, S.; Salsbury, F. R.; Horita, D. A.; Gmeiner, W. H. Zn ${ }^{2+}$ Selectively Stabilizes FdU-Substituted DNA through a Unique Major Groove Binding Motif. Nucleic Acids Res. 2011, 39, 4490-4498.

(34) Gmeiner, W. H.; Trump, E.; Wei, C. Enhanced DNA-Directed Effects of FdUMP[10] Compared to 5FU. Nucleosides, Nucleotides Nucleic Acids 2004, 401-410.

(35) Huschka, R.; Barhoumi, A.; Liu, Q.; Roth, J. A.; Ji, L.; Halas, N. J. Gene Silencing by Gold Nanoshell-Mediated Delivery and LaserTriggered Release of Antisense Oligonucleotide and SiRNA. ACS Nano 2012, 6, 7681-7691.

(36) Huschka, R.; Zuloaga, J.; Knight, M. W.; Brown, L. V.; Nordlander, P.; Halas, N. J. Light-Induced Release of DNA from Gold Nanoparticles: Nanoshells and Nanorods. J. Am. Chem. Soc. 2011 133, 12247-12255.

(37) Mackey, M. A.; Ali, M. R. K.; Austin, L. A.; Near, R. D.; ElSayed, M. A. The Most Effective Gold Nanorod Size for Plasmonic Photothermal Therapy: Theory and in Vitro Experiments. J. Phys. Chem. B 2014, 118, 1319-1326.

(38) Jana, N. R. Gram-Scale Synthesis of Soluble, nearMonodisperse Gold Nanorods and Other Anisotropic Nanoparticles. Small 2005, 1, 875-882.

(39) Ali, M. R. K.; Snyder, B.; El-Sayed, M. A. Synthesis and Optical Properties of Small Au Nanorods Using a Seedless Growth Technique. Langmuir 2012, 28, 9807-9815.

(40) Ghosh, S.; Salsbury, F. R.; Horita, D. A.; Gmeiner, W. H. Cooperative Stabilization of $\mathrm{Zn}^{2+}$ :DNA Complexes Through Netropsin Binding in the Minor Groove of FdU-Substituted DNA. J. Biomol. Struct. Dyn. 2013, 31, 1301-1310.

(41) Scaletti, F.; Kim, C. S.; Messori, L.; Rotello, V. M. Rapid Purification of Gold Nanorods for Biomedical Applications. MethodsX 2014, 1, 118-123.

(42) Maiti, R.; Haldar, S.; Majumdar, D.; Singha, A.; Ray, S. K. Hybrid Opto-Chemical Doping in Ag Nanoparticle-Decorated Monolayer Graphene Grown by Chemical Vapor Deposition Probed by Raman Spectroscopy. Nanotechnology 2017, 28, No. 075707.

(43) Max, J.-J.; Chapados, C. Isotope Effects in Liquid Water by Infrared Spectroscopy. III. $\mathrm{H}_{2} \mathrm{O}$ and $\mathrm{D}_{2} \mathrm{O}$ Spectra from 6000 to 0 Cm(-1). J. Chem. Phys. 2009, 131, No. 184505.

(44) Gao, P. F.; Yuan, B. F.; Gao, M. X.; Li, R. S.; Ma, J.; Zou, H. Y.; Li, Y. F.; Li, M.; Huang, C. Z. Visual Identification of Light-Driven Breakage of the Silver-Dithiocarbamate Bond by Single Plasmonic Nanoprobes. Sci. Rep. 2015, 5, No. 15427. 
(45) Brubacher, J. L.; Vieira, A. P.; Newmark, P. A. Preparation of the Planarian Schmidtea mediterranea for High-Resolution Histology and Transmission Electron Microscopy. Nat. Protoc. 2014, 9, 661673.

(46) Williams, Y.; Byrne, S.; Bashir, M.; Davies, A.; Whelan, A.; Gun'ko, Y.; Kelleher, D.; Volkov, Y. Comparison of Three Cell Fixation Methods for High Content Analysis Assays Utilizing Quantum Dots. J. Microsc. 2008, 232, 91-98.

(47) Schrand, A. M.; Schlager, J. J.; Dai, L.; Hussain, S. M. Preparation of Cells for Assessing Ultrastructural Localization of Nanoparticles with Transmission Electron Microscopy. Nat. Protoc. 2010, 5, 744-757.

(48) Bozzola, J. J. Conventional Specimen Preparation Techniques for Transmission Electron Microscopy of Cultured Cells. Electron Microscopy; Kuo, J., Ed.; Methods in Molecular Biology (Methods and Protocols); Humana Press: Totowa, NJ, 2014; Vol. 1117, pp 1-19.

(49) Ghosh, S.; Ucer, K. B.; D’Agostino, R.; Grant, K.; Sirintrapun, J.; Thomas, M. J.; Hantgan, R.; Bharadwaj, M.; Gmeiner, W. H. NonCovalent Assembly of Meso-Tetra-4-Pyridyl Porphine with SingleStranded DNA to Form Nano-Sized Complexes with Hydrophobicity-Dependent DNA Release and Anti-Tumor Activity. Nanomedicine 2014, 10, 451-461.

(50) Houalet-Jeanne, S.; Pellen-Mussi, P.; Tricot-Doleux, S.; Apiou, J.; Bonnaure-Mallet, M. Assessment of Internalization and Viability of Porphyromonas gingivalis in KB Epithelial Cells by Confocal Microscopy. Infect. Immun. 2001, 69, 7146-7151.

(51) Schneider, C. A.; Rasband, W. S.; Eliceiri, K. W. NIH Image to ImageJ: 25 Years of Image Analysis. Nat. Methods 2012, 9, 671-675. 